\title{
TITLE:
}

\section{Centrifugal-force driven flow in cylindrical micro-channel}

$\operatorname{AUTHOR}(S):$

Maruyama, Toshiro; Maeuchi, Takuto

\section{CITATION:}

Maruyama, Toshiro ...[et al]. Centrifugal-force driven flow in cylindrical micro-channel. Chemical Engineering Science 2008, 63(1): 153-156

\section{ISSUE DATE:}

2008-01

URL:

http://hdl.handle.net/2433/85225

\section{RIGHT:}

Copyright (C) 2007 Elsevier Ltd; この論文は出版社版でありません。引用 の際には出版社版をご確認ご利用ください。; This is not the published version. Please cite only the published version. 


\section{Centrifugal-force driven flow in cylindrical micro channel}

Toshiro Maruyama*, Takuto Maeuchi

Department of Chemical Engineering, Graduate School of Engineering, Kyoto University, Kyoto 615-8510, Japan

Micro-channel flow driven by the centrifugal force was studied by analytical and experimental methods. The analytical expression of flow rate as a function of angular revolution speed was applied to the flow under the condition that the increase in frictional loss due to Coriolis force could be neglected. The experimental verification was made by measuring the outlet volume of water through capillaries that were radially mounted. The experimental results show that cavitation can occur in micro-channel flow driven solely by centrifugal force.

Keywords: Centrifugation; Fluid mechanics; Hydrodynamics; Laminar flow; Microstructure; Momentum transfer

*Corresponding author. Tel.:+81753833054. Fax.: +81753833031. E-mail address: maruyama@cheme.kyoto-u.ac.jp (T. Maruyama) 


\section{Introduction}

Microfluidics, i.e., the control of flow of small volumes of liquids in microscopic channels, is the central technology in the fields of microscale total analysis system ( $\mu$ TAS) or laboratories-on-a-chip. Among the methods reported for microfluidics, electrokinetic control in microfabricated capillaries has received the most attention. However, there are some disadvantages of electroosmosis; a high voltage is required and direct electrical-to-fluid contact results in sensitivity of flow rate to the charge of capillary wall and to the ionic strength and $\mathrm{pH}$ of the solution. As a possible alternative to the established methods of controlling the flow of liquids in microfluidic systems, Duffy et al. (1999) proposed a method where fluids are pumped by centrifugal force through microscopic channels defined in a plastic disk in order to perform complex analytical processes. Zoval \& Madou (2004) introduced the various centrifuge fluidic functions such as valving, decanting, calibration, mixing, metering, heating, sample splitting, and separation. On the basis of experiments and accompanying CFD-simulations, Ducree et al. $(2003,2004)$ demonstrated that high-speed mixing was powered by the Coriolis force (Benton and Boyer, 1966; Mori and Nakayama, 1968; Ito and Nanbu, 1968; Yang et al., 1004) at volume throughputs of up to milliliters per minute and micro channel. To induce transverse mixing by means of the Coriolis force, they went beyond the angular-revolution-speed threshold where the Coriolis force prevails over the centrifugal force (Ducree et al., 2003).

In the literature, Yang et al. (1994) reviewed the fluid mechanical studies on various types of fluid flow inside a rotating channel. In their review, however, there is no report about the centrifugal-force driven flow except a few relating studies, i.e., the studies on the pressure-force driven flows subjected to radial rotation with the longitudinal axis of the flow channel being perpendicular to the axis of rotation. Barua (1954) theoretically simulated a fully developed laminar flow by using an approximate series solution. Benton and Boyer (1966), Mori and Nakayama (1968) and Ito and Nanbu (1971) analyzed fully developed laminar flows, treating the flow as consisting of 
a central core region with a relatively thin layer in the vicinity of the wall.

In this paper, the fluid mechanics for centrifugal-force driven flow are discussed on the basis of theoretical and experimental results under the condition that the Coriolis force could be neglected. Particular emphasis is placed on the prediction of the occurrence of cavitation in micro-channel flow driven solely by centrifugal force.

\section{Analysis}

Fig. 1 shows the coordinate system of the micro channel. The origin of the $\mathrm{x}$-axis is the center of the revolution, and the entrance and exit of the micro channel are situated at $x=x_{0}$ and $x_{\mathrm{L}}$, respectively. In the above-mentioned investigations (Duffy et al., 1999; Zoval and Madou, 2004; Ducree et al., 2003, 2004), only the centrifugal force was considered as an external force. It acts upon the mean radial position of the channel, i.e., $\left(x_{\mathrm{L}}+x_{0}\right) / 2$. Then, the mean velocity $V$ in a pipe of inner diameter $D$ has been expressed as

$$
V=\left(D^{2} / 32 \mu\right)\left[\rho \omega^{2}\left(x_{\mathrm{L}}+x_{0}\right) / 2\right]
$$

Where $\mu$ and $\rho$ respectively are viscosity and density of fluid. $\omega$ is the angular revolution speed and is related to the revolution speed $n$ with the relation

$$
\omega=2 \pi n
$$

When both the static pressure and the centrifugal force at $x$ are taken into account by the authors,

$$
V=\left(D^{2} / 32 \mu\right)\left(-\mathrm{d} p^{\mathrm{t}} / \mathrm{d} x\right)
$$

where $p^{\mathrm{t}}$ is the modified pressure defined as

$$
p^{\mathrm{t}}=p-\left(\rho x^{2} \omega^{2}\right) / 2
$$

Flow conditions under which friction loss by Coriolis force can be neglected are investigated in this contribution. The applicability of this condition will be discussed in the following section.

Substituting the frictional loss of the micro channel expressed as

$$
p_{0}^{\mathrm{t}}-p^{\mathrm{t}}=32 \mu V\left(x-x_{0}\right) / D^{2}
$$


into the integrated Eq. (3) from $x_{0}$ to $x$ yields

$$
p_{0}-p=\left(x-x_{0}\right)\left[32 \mu V / D^{2}-\rho \omega^{2}\left(x+x_{0}\right) / 2\right]
$$

When the static pressures are kept to be equal at $x=x_{0}$ and $x_{\mathrm{L}}$, for example, both $p_{0}$ and $p_{\mathrm{L}}$ are equal to atmospheric pressure, the flow rate is expressible by Eq. (1) and the volumetric flow rate $Q$ is given by the following simple equation,

$$
Q=\rho \pi \omega^{2} D^{4}\left(x_{\mathrm{L}}+x_{0}\right) / 256 \mu
$$

The static pressure in micro channel is obtained from Eqs. (1) and (6) as

$$
p=p_{0}+\rho \omega^{2}\left(x-x_{0}\right)\left(x-x_{\mathrm{L}}\right) / 2
$$

Fig. 2 schematically shows the change in static pressure (Fig. 2(b)) with corresponding change in pressure gradient (Fig. 2(a)). The static pressure changes with second power of $x$, and consequently it takes the minimum value at the mid point between $x_{0}$ and $x_{\mathrm{L}}$. The minimum value of static pressure, $p_{\min }$, is expressed as

$$
p_{\min }=p_{0}-\rho \omega^{2} L^{2} / 8
$$

where $L$ is the length of the micro channel and equal to $\left(x_{\mathrm{L}}-x_{0}\right)$.

Eq. (9) suggests that the cavitation occurs when $p_{\min }$ is below the saturated vapor pressure $p_{\text {sat }}$ of water. The critical revolutions speed $n_{\mathrm{c}}$ defined as the revolution speed at the onset of cavitation is obtained from

$$
n_{\mathrm{c}}=\left[2\left(p_{0}-p_{\mathrm{sat}}\right) / \rho\right]^{1 / 2} / \pi L
$$

The flow becomes gas-liquid two-phase flow at above the critical revolution speed, and the above-mentioned analysis is not applicable. The flow accompanied with cavitation is inferred to be unstable and unsteady in character.

\section{Experiment}

Fig. 3 schematically shows the experimental equipment. A marketed centrifuge was used in the experiments. A stainless steel pipe was used as a micro channel. It was fixed on the rotor with the azimuth that the longitudinal axis is directed in radial direction. A glass tube was used as a storage tank. It was inserted to a slant guide of the rotor. The inner diameters of the stainless steel pipe were 140, 190 and $300 \mu \mathrm{m}$, and 
the lengths were 60,70 and $81 \mathrm{~mm}$, the ratios of length to diameter being 578,426 and 270 for the length of $81 \mathrm{~mm}$. Thus the effect of the flow entrance region becomes smaller with decreasing the pipe diameter.. A stainless steel pipe $(0.5 \mathrm{~mm}$ in inner diameter and $17 \mathrm{~cm}$ long) was used to connect the water in tank and the inlet of the micro channel. Prior to running the experiment, distilled water was filled in both the tank and the pipeline. The radial distance of the center of the water surface of the tank was adjusted to the radial distance of the inlet of the micro channel. The experiments were made at room temperature, $25{ }^{\circ} \mathrm{C}$. During a run, the water was sucked from the tank by the centrifugal force and discharged from the outlet of the micro channel. The accumulative discharge was obtained by weighting the residual water in the tank. A couple of measurements were made with two different processing time of the centrifuge, and the flow rate in steady revolution speed was obtained by dividing the difference in discharge volume by the difference of the processing time.

\section{Results and discussion}

First, consider the volumetric flow rate. Figs. 4 and 5 show the experimental volumetric flow rate $Q$ as a function of revolution speed $n$ for the fixed inner diameter $190 \mu \mathrm{m}$ and the fixed length $81 \mathrm{~mm}$, respectively. The error of the measurements was less than $\pm 5 \%$ except for $D=300 \mu \mathrm{m}$ at $n \geqq 3200 \mathrm{rpm}$. Also shown by solid lines are analytical volumetric flow rate. Evidently, the solid lines correlate the experimental results except $Q>5 \mathrm{~cm}^{3} / \mathrm{s}$, where the measured flow rates are lower than the analytical ones and the differences increase with increasing revolution speed. These differences are attributable to the increase in frictional loss due to Coriolis force (Benton and Boyer, 1966; Mori and Nakayama, 1968; Ito and Nanbu, 1968; Yang et al., 1994). The good agreement between measurement and analysis at $Q \leqq 5 \mathrm{~cm}^{3} /$ min over wide range of revolution speed suggests that the increase in frictional loss is negligibly small for $Q \leqq$ $5 \mathrm{~cm}^{3} / \mathrm{min}$. Indeed, $\operatorname{Re}(=\rho V D / \mu)$ and $\operatorname{Re}_{\omega}\left(=\rho \omega D^{2} / \mu\right)$ for $Q \leqq 5 \mathrm{~cm}^{3} / \mathrm{min}$ are respectively smaller than 727 and 6.71 , and increases in friction factor are within $17.5 \%$ 
according to the following empirical equation (Ito and Nanbu, 1968) for $2.2 \times 10^{2}<R e_{\omega}$ $\operatorname{Re}<10^{7}$ and $\operatorname{Re}_{\omega} / \operatorname{Re}<0.5$.

$$
f / f_{\mathrm{st}}=0.0883\left(R e_{\omega} R e\right)^{1 / 4}\left[1+11.2\left(R e_{\omega} R e\right)^{-0.325}\right]
$$

where $f$ is the friction factor for flow in a rotational straight pipe, and $f_{\text {st }}$ the friction factor for flow in a stationary straight pipe.

Next, consider the critical angular velocity $n_{c}$. The saturated vapor pressure is 3.17 $\mathrm{kPa}$ at a temperature of $25{ }^{\circ} \mathrm{C}$. Eq. (10) shows that the critical angular velocity $n_{c}$ for $L$ $=81 \mathrm{~mm}$ is $3324 \mathrm{rpm}$, and Eq. (7) shows that the micro channel of $D=140 \mu \mathrm{m}$ is the only one that $Q \leqq 5 \mathrm{~cm}^{3} / \mathrm{s}$ at $n=n_{c}$. Fig. 5 shows that the measured flow rates for $L=$ $81 \mathrm{~mm}$ and $D=140 \mu \mathrm{m}$ show a discontinuous change at $n \cong n_{c}$. That is, the flow rate abruptly decreases at $n=3200 \mathrm{rpm}$ and keeps evidently low values compared to the analytical ones. Evidently, the variation of flow rate with $n$ at $n \geqq 3200 \mathrm{rpm}$ is not smooth. The repeated measurements at the same condition showed completely different variations with $n$, indicating that the flow rate cannot be reproduced at $n \geqq 3200 \mathrm{rpm}$.

Thus, it is clear that the cavitation occurs at $n \cong 3200 \mathrm{rpm}$ and that at $n \geqq 3200 \mathrm{rpm}$ the flow becomes gas-liquid two-phase flow, which is unstable and unsteady in character. The fairly well agreement of the value of $n$ with the critical revolution speed indicates that the analysis predicts the occurrence of cavitation with a satisfactory preciseness.

\section{Conclusions}

At small values of $R e$ and $R e_{\omega}$, the frictional losses due to Coriolis force can be neglected in the micro-channel flow driven solely by centrifugal force. The flow rate is a function of angular revolution speed. The cavitation occurs above the critical revolution speed. The analysis predicts the flow rate and the occurrence of cavitation with a satisfactory accuracy under the condition that the increase in frictional loss due to Coriolis force can be neglected. 


\section{Notation}

$D$ inner diameter of pipe

$f$ friction factor for flow in rotational straight pipe,

$f_{\text {st }} \quad$ friction factor for flow in stationary straight pipe

$L \quad\left(x_{\mathrm{L}}-x_{0}\right)$, length of micro channel

$n$ revolution speed

$n_{\mathrm{c}}$ revolution speed at the onset of cavitation

$p \quad$ static pressure

$p_{0} \quad$ static pressure at $x=x_{0}$

$p_{\mathrm{L}} \quad$ static pressure at $x=x_{\mathrm{L}}$

$p_{\min }$ minimum value of static pressure

$p_{\text {sat }} \quad$ saturated vapor pressure of water

$p^{\mathrm{t}} \quad$ modified pressure

$Q \quad$ volumetric flow rate

$\operatorname{Re} \rho V D / \mu$

$\operatorname{Re}_{\omega} \rho \omega D^{2} / \mu$

$V$ mean velocity

$x \quad$ axial direction of micro channel

$x_{0}$ entrance of micro channel

$x_{\mathrm{L}}$ exit of micro channel

\section{Greek letters}
$\mu$ viscosity of fluid
$\rho$ density of fluid
$\omega$ angular revolution speed 


\section{References}

Barua, S.N., 1954, "Secondary flow in a rotating straight pipe,” Proc. Roy. Soc. Lond. A, $227,133$.

Benton, G.S. \& Boyer, D., 1966, "Flow through a rapidly rotating conduit of arbitrary cross-section," J. Fluid Mech. 26, 69-79

Ducree, J. Brenner, T. Glatzel, T. \& Zengerle, R., 2003, “A coriolis-based split-and-recombine laminator for ultrafast mixing on rotating disks," in Proc. Of $\mu$ TAS 2003 (eds. M.A. Northrup, K.F. Jensen, D.J. Harrison), Transducers Research Foundation, San Diego, 603.

Ducree, J. Schlosser, H-P. Hacberie, S. Glatzel, T. Brenner, T. \& Zengerle, R., 2004, "Centrifugal platform for high-throughput reactive micromixing," in Proc. Of $\mu$ TAS 2004 (eds. T. Laurell, J. Nilsson, K.F. Jensen, D.J. Harrison, J.P. Kutter), The Royal Society of Chemistry, Cambridge, 554.

Duffy, D.C. Gillis, H.L. Lin, J. Sheppard, Jr. N.F. \& Kellogg, G.J., 1999, "Microfabricated centrifugal microfluidic systems: Characterization and multiple enzymatic assays," Anal. Chem. 71, 4669-4678.

Hacberie, S. Brenner, T. Schlosser, H-P. Zengerle, R. \& Ducree, J., 2005, “Centrifugal micromixer," Chem. Eng. Technol. 28, 613-616.

Ito, H. \& Nanbu, K., 1971, "Flow in rotating straight pipes of circular cross section," Trans ASME, J. Basic Enging 93, 383-394.

Mori, Y. \& Nakayama, W., 1968, “Convective heat transfer in rotating radial circular pipes" ( 1st Report, Laminar region). Int. J. Heat Mass Trans. 11, 1027-1040.

Yang, W-J. Fann, S. \& Kim, J.H., 1994, "Heat and fluid flow inside rotating channels," Appl. Mech. Rev. 47, 367-396.

Zoval, J.V. \& Madou, M.J., 2004, “Centrifuge-based fluidic platforms,” Proc. IEEE 92. 140-153. 
Figure caption

Fig. 1 Coordination system about micro channel

Fig. 2 Schematic representations of changes in (a) pressure gradient with and (b) static pressure

Fig. 3 Schematic (a) plane view and (b) inclined side view of experimental equipment

Fig. 4 Volumetric flow rate $Q$ as a function of revolution speed $n$ for fixed inner diameter $D=190 \mu \mathrm{m}$

Fig. 5 Volumetric flow rate $Q$ as a function of revolutions speed $n$ for fixed length $L=$ $81 \mathrm{~mm}$ 


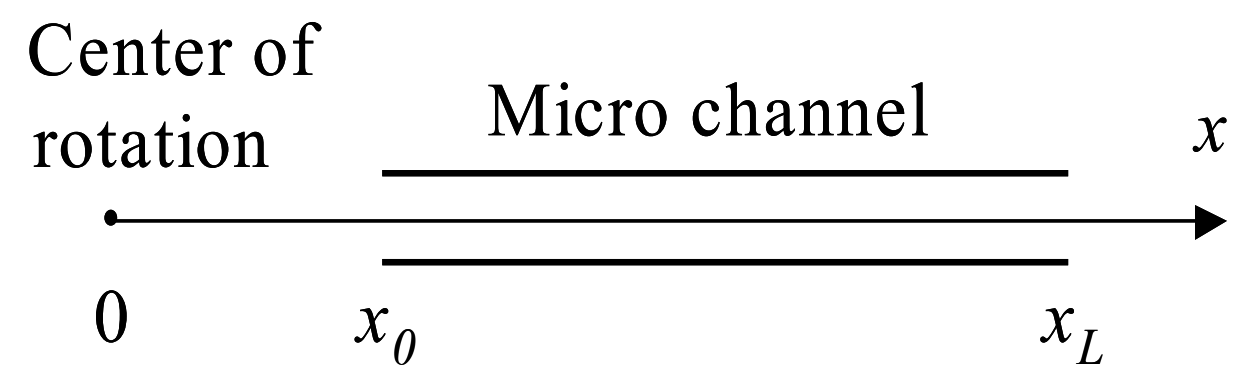

Fig. 1 


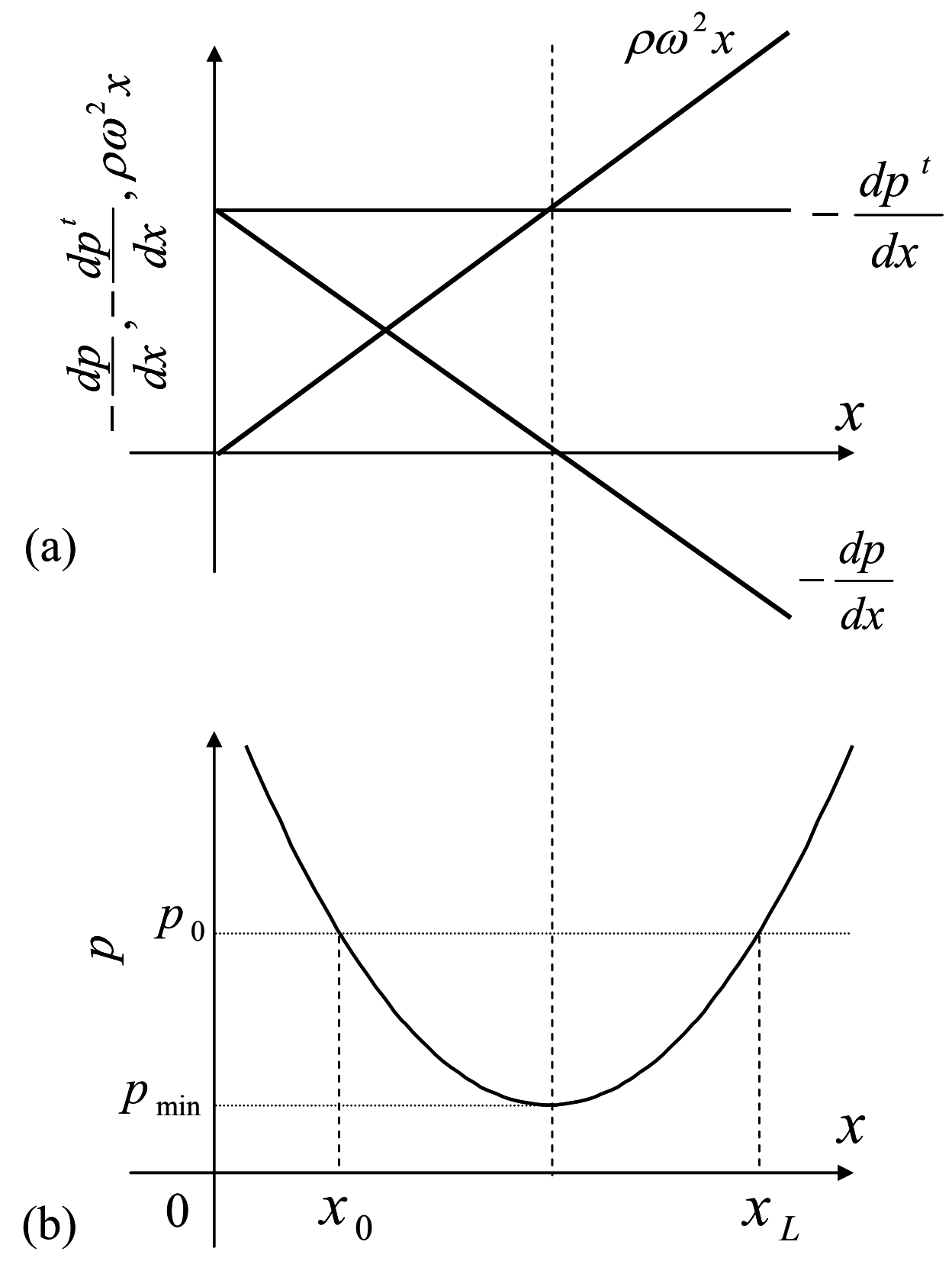

Fig. 2 
(a)

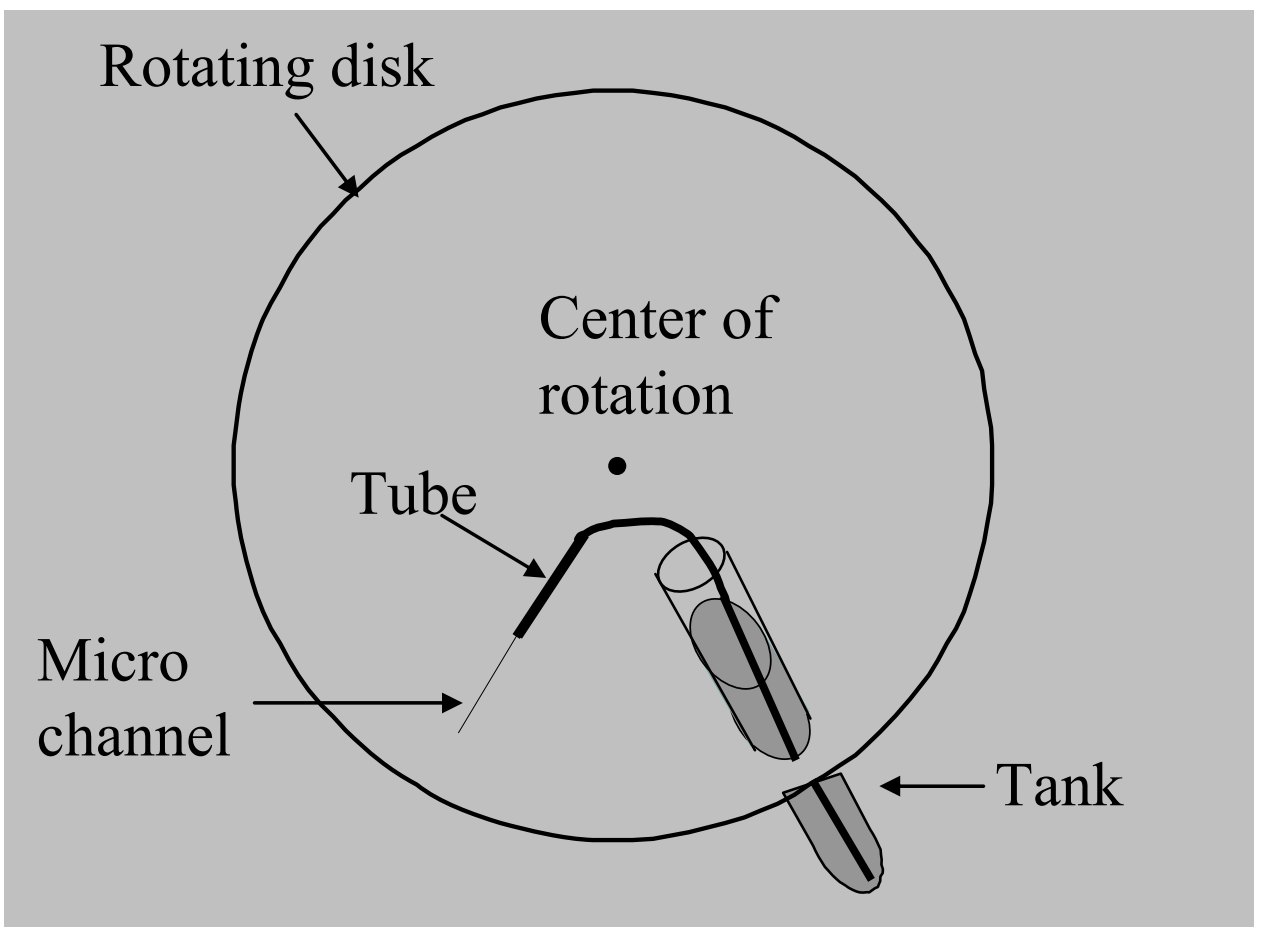

Axis of rotation

(b)

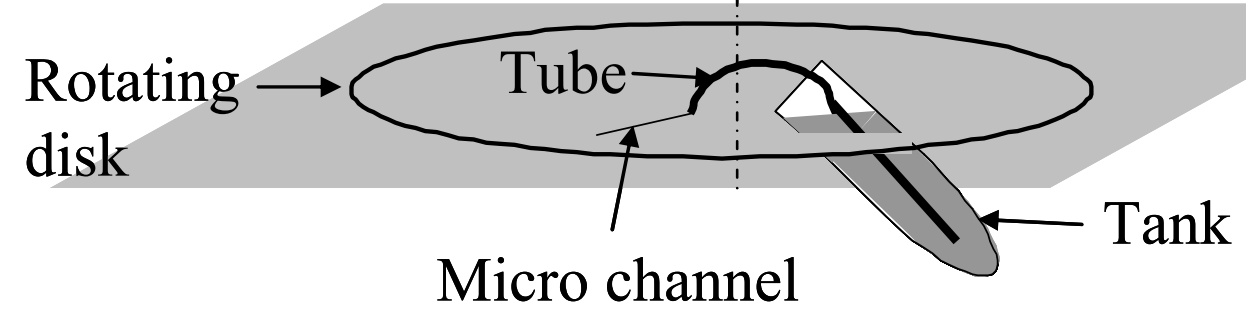

Fig. 3 


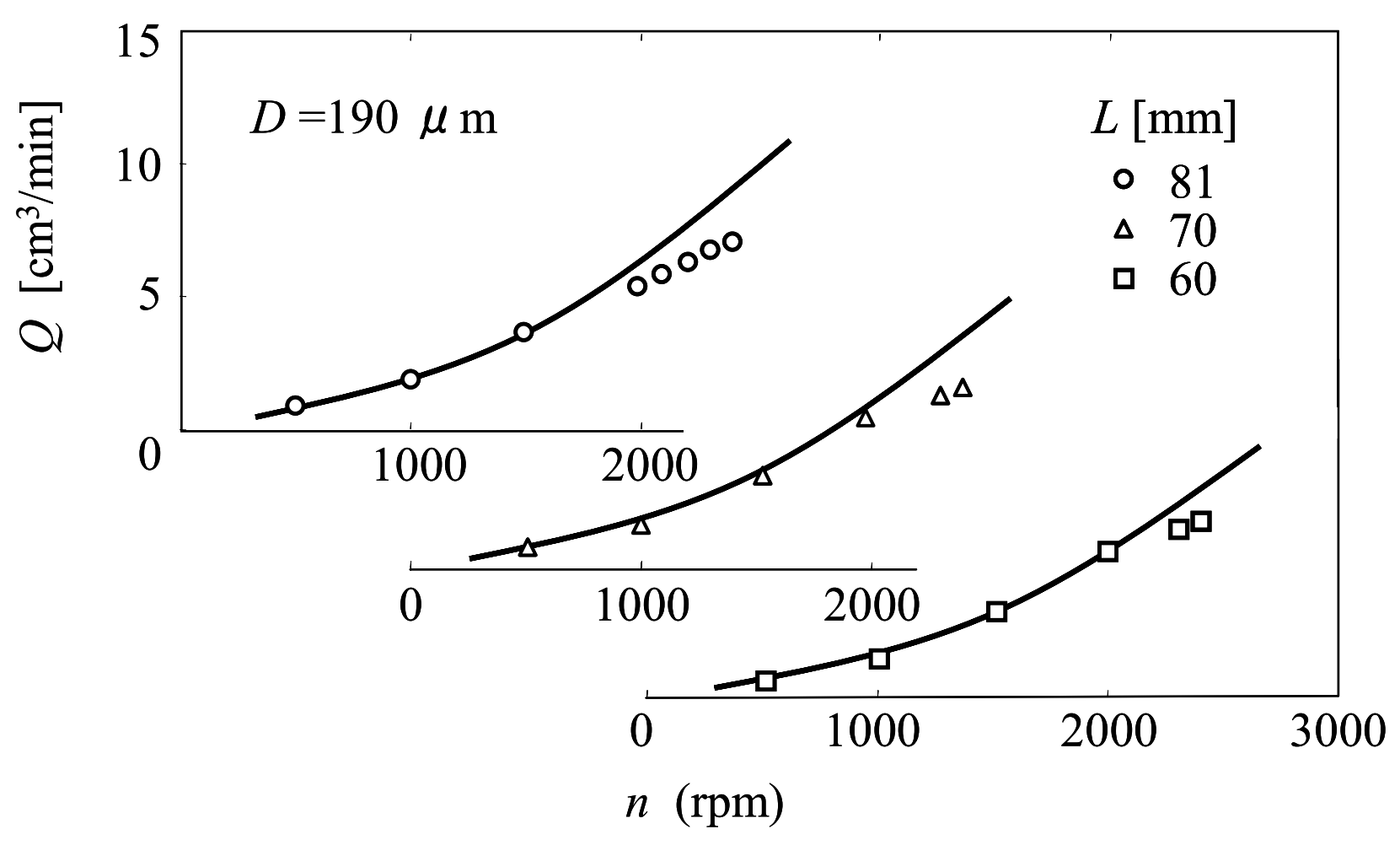

Fig.4 


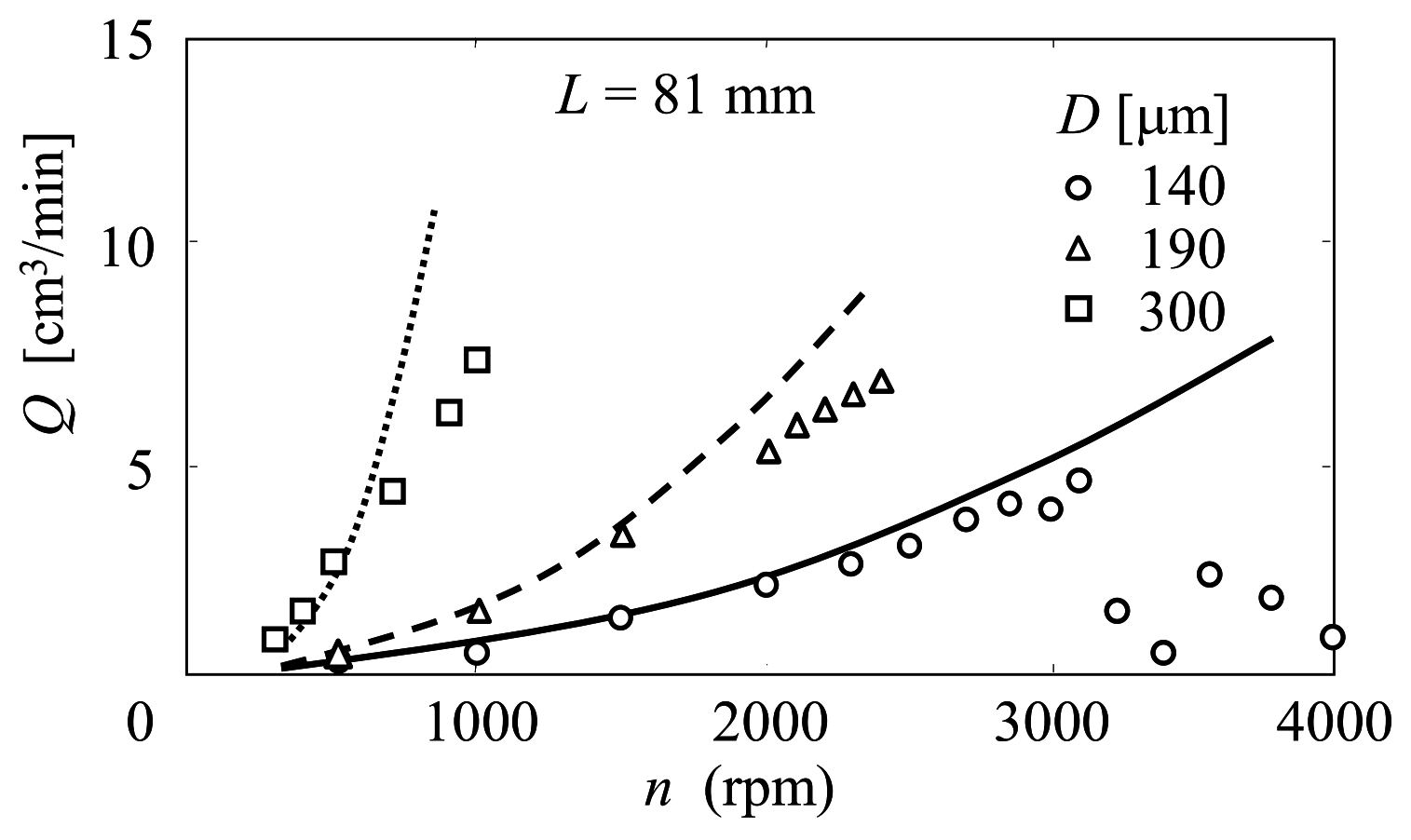

Fig. 5 